\title{
A multi-objective optimization model of the partner selection problem in a virtual enterprise and its solution with genetic algorithms (by Zhao Fuqing; Hong Yi; Yu Dongmei)
}

John B. Davies

Published online: 22 May 2008

(C) Springer-Verlag London Limited 2008

Erratum to: Int J Adv Manuf Technol (2006) 28:1246-1253

DOI 10.1007/s00170-004-2461-4

Parts of this paper were taken from the paper of Ip et al., entitled: "Genetic algorithm solution for a risk-based partner selection problem in a virtual enterprise.", Computers and Operations Research, 30 (2003), 213-231, without appropriate credit given in the article's references.

The online version of the original article can be found at http://dx.doi. org/10.1007/s00170-004-2461-4.

J. B. Davies $(\bowtie)$

Bedford, UK

e-mail: BJohnDavies@aol.com 